\title{
EDUCAÇÃO CONTEXTUALIZADA E EDUCAÇÃO GLOCAL: PERTENCIMENTO NA MUNDIALIZAÇÃO OU FORMAÇÃO PARA UMA CIDADANIA PLANETÁRIA
}

Edmerson dos Santos Reis ${ }^{41}$

\begin{abstract}
Resumo
Resultado da minha participação em uma mesa redonda com o mesmo título, que aconteceu durante o I Colóquio Brasil/Itália, cujo tema foi "Educação Contextualizada e o diálogo intercultural na implementação de novas estratégias de internacionalização da extensão no PPGESA/DCH-III/UNEB”, realizado no dia 21 de agosto de 2019, no campus III da UNEB, em Juazeiro - BA. O trabalho traz uma reflexão que busca estabelecer a aproximação entre a Educação Contextualizada e a Educação Glocal, com vistas a atender às necessidades de construção de um processo formativo das atuais gerações, por meio da educação, contribuindo assim com a possibilidade do sujeito sentirse pertencente ao seu mundo, ao seu contexto de vida, sem perder de vista a perspectiva da mundialização em que vivemos e a condição de uma formação que desperte nesse sujeito o sentimento e a atuação em favor de uma cidadania planetária. Para dar conta do diálogo aqui proposto, lançamos mão de algumas referências como Zaoul (2003), Santos (2006), Mintegáguia (2012), Sousa Santos (2002) e Reis (2011), que contribuem para estabelecer esta rede de sentidos, para a partir daí refletirmos alguns desafios postos à escola e a Educação na tentativa de, nas suas práxis, efetivarem uma ação formativa alicerçada no pertencimento local, mas à favor de uma cidadania planetária.
\end{abstract}

Palavras-chave: Educação contextualizada. Educação Glocal. Pertencimento.

\section{EDUCAZIONE CONTESTUALIZZATA E EDUCAZIONE GLOCALE: APPARTENENZA ALLA MONDIALIZZAZIONE O FORMAZIONE PER UNA CITTADINANZA PLANETARIA}

\section{Sintesi}

Risultato della mia partecipazione a una tavola rotonda con lo stesso titolo, svoltasi durante il $1^{\circ}$ Colóquio Brasil/Itália, il cui tema era 'Educazione contestualizzata e dialogo interculturale nell'implementazione di nuove strategie di internazionalizzazione della terza missione accademica al PPGESA/DCH-III/UNEB', Tenutosi il 21 agosto 2019, nel Campus III dell'UNEB, a Juazeiro - BA. Il lavoro riporta una riflessione che cerca di stabilire l'approssimazione tra l'educazione contestualizzata e l'educazione glocale, al fine di soddisfare le esigenze di costruzione di un processo formativo delle generazioni

\footnotetext{
${ }^{41}$ Professor Adjunto do Departamento de Ciências Humanas - Campus III da Universidade do Estado da Bahia - UNEB, Pedagogo, Mestre em Educação, Especialista em Desenvolvimento Local, Doutor em Educação pela Universidade Federal da Bahia - UFBA, Membro da Secretaria Executiva da Rede de Educação do Semiárido Brasileiro -RESAB e do Fórum Nacional de Educação do Campo - FONEC. Professor do Programa de Pós-graduação - Mestrado em Educação, Cultura e Territórios Semiáridos PPGESA. Líder do Grupo de Pesquisa Educação Contextualizada, Cultura e Território - EDUCERE. Email: edmerson.uneb@gmail.com
} 
attuali, attraverso l'educazione, contribuendo così alla possibilità che il soggetto si senta appartenente al suo mondo, al suo contesto di vita, senza perdere di vista la prospettiva della globalizzazione in cui viviamo e la condizione di una formazione che risvegli in questo soggetto il sentimento e l'attuazione pratica a favore di una cittadinanza planetaria. Per rendere conto del dialogo qui proposto, abbiamo considerato alcuni riferimenti come Zaoul (2003), Santos (2006), Mintegáguia (2012), Sousa Santos (2002) e Reis (2011), che contribuiscono a stabilire questa rete di significati, per riflettere, partendo da questi, su alcune sfide poste alla scuola e all'educazione, nel tentativo di svolgere un'azione di formazione, nelle loro prassi, basata sull'appartenenza locale ma a favore di una cittadinanza planetaria.

Parole chiave: Educazione contestualizzata. Educazione GloCale. Appartenenza.

\title{
CONTEXTUALIZED EDUCATION AND GLOCAL EDUCATION: BELONGING TO WORLDWIDE OR EDUCATION FOR A PLANETARY CITIZENSHIP
}

\begin{abstract}
Result of my participation in a round table with the same title, held during the 1st Colóquio Brasil / Itália, whose theme was 'Contextualized education and intercultural dialogue in the implementation of new strategies of internationalization of the third academic mission at PPGESA / DCH- III / UNEB', held on August 21, 2019, on Campus III of the UNEB, in Juazeiro - BA. The work reports a reflection that tries to establish the approximation between contextualized education and GloCal education, in order to meet the needs of building an educational process for the current generations, thus contributing to the possibility that the subject feels he belongs to his world and to his context of life, without losing sight of the perspective of the globalization in which we live and the condition of an education that awakens the feeling and the practical actualization in favor of a planetary citizenship. To account for the dialogue proposed here, we have considered some references such as Zaoul (2003), Santos (2006), Mintegáguia (2012), Sousa Santos (2002) and Reis (2011), which contribute to establishing this network of meanings, and to reflect on some challenges posed to school and education, in an attempt to carry out a formative action, in their practices, based on local belonging but in favor of a planetary citizenship.
\end{abstract}

Keywords: Contextualized Education. Glocal Education. Membership.

\section{Introdução}

Da minha aldeia vejo quanto da terra se pode ver do Universo... Por isso a minha aldeia é tão grande como outra terra qualquer, porque eu sou do tamanho do que vejo e não do tamanho da minha altura...

(Alberto Caeiro, 1946, p.32) 
O presente texto é fruto da minha participação em uma mesa redonda com o mesmo título, que aconteceu durante o I Colóquio Brasil/Itália, cujo tema foi "Educação Contextualizada e o diálogo intercultural na implementação de novas estratégias de internacionalização da extensão no PPGESA DCH-III/UNEB”, ocorrido no dia 21 de agosto de 2019, no campus III da UNEB, em Juazeiro - BA. O trabalho traz uma reflexão que busca estabelecer a aproximação entre a Educação Contextualizada e a Educação Glocal, com vistas a atender às necessidades de construção de um processo formativo das atuais gerações, por meio da educação, contribuindo assim com a possibilidade do sujeito sentir-se pertencente ao seu mundo, ao seu contexto de vida, sem perder de vista a perspectiva da mundialização em que vivemos e a condição de uma formação que desperte nesse sujeito o sentimento e a atuação em favor de uma cidadania planetária.

Para dar conta do diálogo aqui proposto, lançamos mão de algumas referências como Zaoul (2003), Santos (2006), Mintegáguia (2012) e Sousa Santos (2002), Reis (2011), que contribuem para estabelecer esta rede de sentidos, para a partir daí refletirmos algumas experiências concretas que tentam nassuas práxis efetivar uma ação educativa alicerçada nessa compreensão. A compreensão que se chega é de que, na atualidade da complexidade do mundo, das mais diversas facetas do sistema capitalista em que vivemos, que oprime, dilacera comunidades, culturas e natureza, tudo é transformado em moeda, em lucro, pois é o que importa nesse sistema. Contrária essa linha, a Educação contextualizada fortalece as redes locais e coloca os sujeitos em conexão com o mundo mais amplo, mas a partir do seu mundo, ou seja, numa abordagem glocal, o que parece ser o caminho necessário à construção de um outro mundo possível.

\section{O local como submissão ao global, negação da aldeia}

Usando uma metáfora da aldeia para ir refletindo as relações da educação com os contextos locais, essa poderia ser compreendida como o lugar em que os sujeitos vivem, estabelecem suas as relações, afirmam suas culturas enquanto comunidade, colocam-se no mundo desde esse lócus. A aldeia está ligada ao global por todas as mediações possíveis que atravessam-na: política, cultural, econômica, social, ética, entre outras. Mas, a escola e os espaços de formação dos povos e dos professores da escola, presentes na aldeia, não conseguem dialogar com os saberes do local, pois, pelas imposições globalizantes, esses devem apreender e aprender apenas o saber "maior” e global. 
Nesse sentido, a escola nega a aldeia, nega seu povo, sua cultura, seu modo de sersendo-no-mundo, pois para o sistema de ideias colonizadoras e alienantes, a escola deve ser um espaço da transmissão de um saber "neutro", que reproduz uma cosmovisão que atende apenas aos interesses daqueles que emanam a ordem do saber, a maneira como deve funcionar a economia, e a cultura que deve ser considerada como a ideal, a cultura dominante. Ou seja, o que temos então é a negação da vida como ela é, enquanto deveria ser o elemento formativo da continuidade da vida da aldeia.

Hassan Zaoual, em seu livro Globalização e diversidade cultural, vai destacar que:

Na medida em que cresce o global, também se amplia o sentimento do local. As razões deste paradoxo são múltiplas, entre as quais mencionamos a seguinte: a globalização, sinônimo de mercantilização do mundo, introduz localmente um tipo de incerteza e de vertigem na mente humana. Uma das maneiras de reagir a isso consiste na busca da certeza de que somente a proximidade pode garantir, até certo ponto, $\mathrm{o}$ sentimento de pertencer. (ZAOUAL, 2003, p.21).

Essa maneira de compreender a relação local-global vai reafirmar que, numa busca de centralidade do global, todas as dimensões do local se submetem ao global, sendo apenas a corrente auto organizadora dos sujeitos locais, na busca de afirmação dos seus modos de existir nos seus mundos que poderá tentar reverter esta anulação de si para promover a afirmação do pertencer a aldeia, ao lugar. Ou seja, não serve à aldeia este modelo, esta forma de produção do mundo, de organização da vida e dos modos de existir, sempre subordinados aos interesses dos que detêm o poder.

A premissa que passa a valer aqui é a de que o local fica reduzido à submissão daquilo que representa os ditames globais. Assim, não se forma para uma cidadania planetária, mas para a obediência. Como não há complementaridades, os filhos da aldeia passam a ter a cabeça formada apenas pelo saber do global.

Para Zaoual(2003), a ciência ocidental e, especialmente a econômica, tem comandado a civilização global.

Abstrata, dedutiva, e dividida em especializações estanques, ela empurra a humanidade em direção a um desastre social e ambiental.Apesar dos sucessivos fracassos econômicos transpostos nos países do Sul e, também, do esgotamento do mito do progresso nos países mais adiantados na aventura do desenvolvimento, as crenças científicas vinculadas a essa ciência estão resistindo à necessidade de uma mudança profunda. (ZAOUAL, 2003, p. 18). 
Sem que que haja uma mudança radical da cosmovisão da maneira ocidental de ciência que até então foi negligenciando os contextos diversos e simplificando-os aos seus modos de interpretação, não haverá a construção das bases de uma nova ciência que carregue em si outras cosmovisões que denunciam e explicam os mundos por outras lógicas que não se enclausuram em um modelo único de perceber a realidade, mas as realidades e quantas interpretações possíveis sejam realizadas delas. Como nos alerta Souza Santos (2002, p.238),

Para combater o desperdício da experiência social, não basta propor um outro tipo de ciência social. Mais do que isso, é necessário propor um modelo diferente de racionalidade. Sem uma crítica do modelo de racionalidade ocidental dominante pelo menos durante duzentos anos, todas as propostas apresentadas pela nova análise social, por mais alternativas que se julguem, tenderão a reproduzir o mesmo efeito de ocultação e descrédito.

Como é possível constatar, a tarefa da desconstrução não é tão fácil, mas é a busca de novos caminhos e possibilidades de leitura e interpretação do mundo e das suas vertentes, dando margem à escuta das diferenças e às aprendizagem que essas carregam em si, que nos mostrará vertentes a serem seguidas na tentativa de promover a desocultação e a credibilidade a outros tantos modos de produção do saber e da leitura da realidade, privilegiando saberes até então desconsiderados e considerados menores.

Trazendo para o campo da educação, das práticas educativas e dos desafios das reorientações curriculares e pedagógicas, para se construir indícios de uma escola que vai mudando e que começa a compreender os desafios do seu tempo, da sociedade e de um mundo intercultural, para Carvalho e Reis (2013, p. 27),

Faz-se uma tarefa para a educação recuperar o sujeito pensante, considerar o conjunto das suas faculdades diante da realidade complexa do mundo atual. Um desafio epistêmico e metodológico para a Ciência e a sociedade contemporâneas, marcadas ainda pela racionalidade moderna e técnica, com métodos mais técnicos e menos metodológicos. Faz-se preciso colocar o sujeito em relação à complexidade da rede entre o local-global-local. A contextualização concebida a partir da noção de contexto (que provém do Latim - Contextus, ūs- reunião, conjunto, entrelaçar, tecer, tessitura), apoiada na leitura de Morin (1998), que se refere a contexto como sendo a realidade a partir de onde ela se tece e se entrelaça de forma complexa. Uma ideia que se sustenta na noção de complexus como a complexidade da unidade para a diversidade, como postula o autor. A noção da complexidade da realidade, concebida na sua dimensão una e diversa, cujos opostos 
guardam entre si as interações dinâmicas que compõem a unidade e marcam a diversidade.

Sem essa possibilidade de articulação, está longe se evidenciar nas práticas educativas os indícios que nos mostram a mudança e a possibilidade do saber ter sentido e ser significado no contexto, na vida e no sujeito, como algo que ajuda a entender o mundo no qual se transita, ou como Freire nos ajudava a entender, ao refletir sobre o pensar certo, compreendendo que o saber da ciência não deve chegar para anular os saberes da cultura local, mas em consonância com ele, ajudar no desvelamento do mundo, para se sair de uma postura acrítica em direção a uma compreensão mais complexa da vida e de todos os seus fenômenos naturais, físicos, biológicos etc.

Exige prática e teoria sempre em unidade. Não há prática sem teoria nem teoria sem prática. Pensar certo significa procurar descobrir e entender o que se acha mais escondido nas coisas e nos fatos que nós observamos e analisamos. Descobrir, por exemplo, que não é o "mau olhado" o que está fazendo Pedrinho triste, mas a verminose. Não será, portanto, somente com as benzeduras que devolvemos a alegria a Pedrinho, mas com a orientação médica. (Freire, 1993, p.77).

\section{O local como o próprio espelho da aldeia}

Com essa mesma analogia da aldeia e dos seus sujeitos, pensamos o seguinte: e se os filhos da aldeia rompessem, em uma insurgência compreensiva, e construíssem os seus saberes formativos apenas com os saberes da aldeia?

Para alguns que compreendem os processos de colonização/descolonização, colonialidade/decolonialidade apenas como artifícios opositores e que saindo de um perspectiva para a outra o problema estaria resolvido, talvez esse rompimento e insurgência por parte dos filhos da aldeia resolvesse, mas não é tão simples assim, pois a aldeia por si só não daria conta do mundo, visto que, a opção que se faz é de negar os contextos mais amplos, mais diversos, os mundos, as culturas, para viver a sua clausura.

Os filhos da aldeia formados com a cabeça apenas na aldeia, desconheceriam os problemas do mundo que chegam a aldeia. Isso não seria o suficiente, pois, haveria apenas a inversão da lógica, de uma racionalidade que antes era submissa ao outro e que agora nega o outro, mesmo ele existindo e perpassando o mundo da aldeia. Como defende Souza Santos (2002), não basta apenas propor outro tipo, é preciso construir outro modelo 
diferente de racionalidade, mais includente e que permita o diálogo com os demais saberes e contextos diversos.

\section{A educação contextualizada unida à perspectiva da Educação Glocal: a aldeia conectada ao global, mas afirmando-se}

E se os filhos da aldeia compreendessem e definissem que para não se isolarem do global precisariam reconstruir a escola, o seu currículo e formação do seu povo com os pés no chão da aldeia, mas conectados ao global?

Dessa forma, os filhos da aldeia estariam conectados ao global sem deixarem de ser da aldeia, mas cidadãos do mundo, ou ainda, forjariam nos seus processos formativos a base para a construção, a partir dos saberes e conhecimentos da aldeia, de uma cidadania planetária. Aqui teríamos o ser sendo no mundo na construção da sua historicidade, antenado no tempo histórico da sua comunidade e do mundo, no diálogo com a história e as temporalidades da humanidade. É essa complexidade pela qual se advoga a Educação Contextualizada para a convivência com o Semiárido Brasileiro, cujo lugar histórico, cultural e simbólico, ponto de partida da construção e ampliação do saberes e conhecimentos diversos é o Semiárido, essa é a aldeia da qual passamos pensar. Desse modo, a Educação contextualizada reafirma o diálogo dos saberes locais e globais, ou ainda a perspectiva da educação glocal, como afirmar Reis (2011, p. 19).

Nessa dinâmica, mediada pela aprendizagem dos saberes e conhecimentos diversos, os sujeitos da aprendizagem passam, a partir dos conhecimentos locais, a aprofundar o conhecimento do mundo em que vivem, mantendo-se em constante sintonia com o mundo mais global, de maneira contextualizada, sem que um saber prevaleça ou imponha-se ao outro.

Assim, a Educação contextualizada reafirma o diálogo dos saberes locais e globais permitindo que o conhecimento trabalhado pela escola, seja ela pública, privada, comunitária, beneficente ou confessional, consiga desenvolver um caminho formativo, intencional e não mecânico, que a partir da provocação reflexiva e do questionar sempre a realidade na qual encontra-se inserida, microcosmo do complexo maior, possa-se questionar as interferências do global no seu mundo e assim, compreender-se nesse, não como resultado da história, mas como agentes construtores dela.

A aldeia, compreendida por Zaoul (2006) como o sítio, não se faz isolada, não é uma ilha "separada" do restante do território, pois, mesmo pelo território submerso, as 
ilhas se conectam ao território do qual aparentemente parece estar "separada" pelas águas, mas é apenas um equívoco de compreensão. A aldeia mantém-se firmada nos seus saberes e fazeres, recebe as influências mais amplas, muda, atualiza as suas visões, seus modo de ser e de se fazer como tal, uma vez que a temporalidade é esse vínculo atualizante e constante do presente, com o passado e o futuro, mas no qual o território se faz é a parada sobre a qual se reflete a si mesmo e se reconhece ou se provoca o estranhamento entre si o mundo mais amplo. De tal modo,

Torna-se lógico que a escala mais pertinente seja a do território. Enquanto espaço simbólico e cognitivo, o sítio magnetiza os comportamentos e marca profundamente os códigos, as normas, as convenções, as instituições locais e, finalmente, o meio local circundante. (ZAOUAL, 2006, p.18).

Ou ainda, como defendia Santos (2006), "O centro do mundo está em todo lugar. O mundo é o que se vê de onde se está", e é daqui que se pensa o ali e o acolá e retornamos para o aqui, pois é nele que a vida se faz, que os sujeitos significam e ressignificam o seu mundo, não devendo a escola ficar alheia a esse entendimento. Corroborando com esse ponto de vista, REIS (2011, p. 184-185), referindo-se à escola do campo contextualizada, defende o seguinte:

Compreende-se então, que nesta prática, ao contexto local é dedicado o lugar da articulação constante dos saberes mais diversos (locais e globais), que por intermédio do fazer pedagógico vai permeando as relações escola-comunidade e o próprio sentido da Educação do Campo, em que a tematização e a busca da compreensão são os fundamentos da intenção educativa. Nessa lógica não se promove nem um currículo localista, nem um currículo universalista, mas exercita-se sempre a tentativa de efetivação de um currículo conectado com os contextos diversos, sem aprisionamentos locais ou generalismos globalizantes e excludentes.

Indubitavelmente, não há formação planetária sem que se dedique atenção às dimensões do local e do território que dão o sentido do ser e do pertencer a algum lugar. Mas, o processo de construção do saber e da socialização do conhecimento não pode ter o lugar como a negação do mundo, tornando-se a clausura, a bolha desconectada. Por outro lado, o global também, não pode se configurar como a negação do ser, do lugar, do território.

O conhecimento de si, do seu mundo, do seu lugar é ponto de partida para a ação intercultural e a materialização da Educação Glocal/Contextualizada, que precisa assumir 
esse desafio de não permitir o apagamento do outro, do território, do ethos. Ou melhor, como destaca Anália Mintegáguia(2012, p. 49), no texto nuevospardigmas: educación y buenvivir:

Es importante formar a laciudadanía como parte de una nación, de unterritorio y del mundo. Para ello es preciso construir el concepto de ciudadanía universal, enun mundo con alta movilidad individual, voluntaria y forzada. La construcción de tal ciudadaníapasa por descifrarlos relatos históricos que han sido invisibilizados u ocultos, que remiten a una condición humana básica: ciudadanos de latierra.

Para a autora, o ensino numa perspectiva da cidadania planetária, universal deve trazer nas suas preocupações, nos seus currículos e prática educativas a formação integral do sujeito para a vida, pois, aprender nessa compreensão exigesaber relacionar-se consigo, com os outros, e portanto, o acesso a expressões como a arte, o cinema, a literatura, o teatro, a cultura a gastronomia são partes dessa maneira de pensar e agir no mundo que envolvem parte dessas escolas da vida e que não podem ficar fora do projeto de uma escola nova, antenada às necessidades do diálogo intercultural e da garantia da alteridade, sem a qual não conseguiremos construir as bases de uma sociedade com justiça social e equilíbrio entre as nações e grupos diversos.

\section{Para concluir}

As reflexões que permearam a realização da mesa temática que originaram este escrito provocam o repensar do modelo e concepção de escola e do sentido da educação que se processa nos sistemas educativos, pois, não se pode mais justificar o abismo que separa a educação dos mais necessitados da educação dos que têm a condição de acessar escolas e sistemas educativos com uma qualidade educativa melhor e com vistas a trazer para as reformas curriculares a preocupação com a vida, com os contextos diversos e com os elementos que constituem as suas especificidades culturais, territoriais e de pertencimento dos seus sujeitos.

Repensar a educação com vistas à construção de uma cidadania planetária, primeiramente é preciso encontrarmos um ponto de equilíbrio entre escola, saberes das comunidades e saberes das ciências. Não se pode continuar tendo na escola um complexo educativo a favor do apagamento dos sujeitos que a ela acessam e dos seus saberes culturais. 
A escola precisa ser o espaço do intercâmbio dos saberes, da mediação entre aquilo que já se sabe e que já se chega sabendo na escola e aquilo que será preciso ser ampliado enquanto repertório cultural a ser acessado e necessário à inserção mais compreensiva e critica acerca do mundo que nos cerca e que vai além do estrato local.

Assim, estruturar bases para a construção de educação contextualizada e também glocal é o desafio que passa por contextualizar os processos formativos, perceber que a educação e a escola devem ir além de apenas socializar conhecimentos prontos e acabados, mas ter nos espaços e contextos nos quais os processo educativo acontecem, a referência da qual se parte para a compreensão dos sentidos e significados do conhecimento que se acessa. Fora desse intenção, a ação pedagógica passa a ser apenas reprodutivista, sem possibilidade de um diálogo intercultural e de formação para uma cidadania planetária, ou seja, do cidadão do mundo, que do lugar em que pisa, com todas as suas representações, limites e potencialidades, será capaz de compreender as diferenças dos outros contextos e inserir-se nestes sem que se sinta inferior, mas de igual para igual.

Esse é o desafio maior do diálogo da Educação Contextualizada com a Educação Glocal, cuja finalidade maior é a promoção da alteridade e da construção de uma sociedade com justiça social, economia justa, democracia e com simetria mundial. Desafio utópico, mas necessário para nos mover em busca de um diálogo entre os conhecimentos diversos cujo ponto de partida deve ser sempre a vida, a realidade dos sujeitos e dos seus contextos. Sem isso, teríamos apenas a reprodução das intenções de um sistema que já se faz esgotado e que provou não ser o necessário para a construção de um mundo melhor, do forjar de uma cidadania planetária com pertencimento ao mundo sobre o qual transito.

\section{Referências}

CARVALHO, Luzineide Dourado; REIS, Edmerson dos Santos. Educação contextualizada para a convivência com o semiárido brasileiro: fundamentos e práticas. In: Caderno Multidisciplinar - Educação e Contexto do Semiárido Brasileiro, Ano 08, No07, Setembro de 2013 [pág. 23-40]. Juazeiro - Bahia: Selo Editorial Resab, 2013.

FREIRE, Paulo. A importância do ato de ler: em três artigos que se completam. 28 ed. (Coleção questões da nossa época). São Paulo: Cortez, 1993.

MINTEGUIAGA, Analía. Nuevos paradigmas: educación y buenvivir. In: Educación y buenvivir: reflexiones sobre suconstrucción. 1ra. Edición, Marzo de 2012, Serie Reflexiones. Equador: Quito: Activa: Contrato Social por laEducación, 2012. 
REIS, Edmerson dos Santos. Educação do Campo: escola, currículo e contexto. Juazeiro: Printpex/ADAC/UNEB/DCH-III/NEPEC-SAB, 2011.

SANTOS, Milton. O centro do mundo está em todo lugar. O mundo é o que se vê de onde se está. In: TENDLER, Silvio. Encontro com Milton Santos ou o Mundo Global Visto do Lado de Cá. (Documentário). Brasil, 2006.

O GUARDADOR DE REBANHOS". In: Poemas de Alberto Caeiro. Fernando Pessoa. (Nota explicativa e notas de João Gaspar Simões e Luiz de Montalvor.) Lisboa: Ática, $1946\left(10^{a}\right.$ ed. 1993).

SOUSA SANTOS, Boaventura de. Para uma sociologia das ausências e uma sociologia das emergências. Revista Crítica de Ciências Sociais [Online], No 63, Ano 2002, colocado online no dia 01 outubro 2012, criado em 19 abril 2019. URL: http://journals.openedition.org/rccs/1285; acessado em 03 de setembro de 2019.

ZAOUAL, Hassan. Globalização e diversidade cultural. (Questões da nossa época). São Paulo, Ed. Cortez coleção, 2003. 